\title{
Role of Color Doppler Ultrasound in Antenatal Diagnosis of Placenta Accreta in Patients with Previous Cesarean Scar \\ S.A.Saad ${ }^{1,}$ M.A.Mahmoud ${ }^{1}$, A.M.Bayoumi ${ }^{1}$ and M.A.Sallam ${ }^{2}$ \\ ${ }^{1}$ Obstetrics,Gynecology Dept., Faculty of Medicine, Benha Univ., Benha, Egypt \\ ${ }^{21}$ Obstetrics,Gynecology .kafr elzayat general hospital \\ E-Mail: mona-salaam@gmail.com
}

\begin{abstract}
Morbidly adherent placenta is asignificant cause of maternal morbidity, mortality and massive obstetric hemorrhage. It is defined as an abnormal placental adherence either in whole or in part of the placenta to the underlying uterine wall. It is a potentially life threatening condition responsible for 7-10\% of maternal mortality.Is to evaluate the accuracy of Color Doppler Ultrasonography in antenatal diagnosis of placenta previa accreta in patients with previous cesarean sections. The study included 60 pregnant females after 28 week of gestation from obstetrics and gynecology department of Banha University hospital during a period from ( $1^{\text {st }}$ of December 2018 to $30^{\text {th }}$ November 2019) with suspected history and ultrasonographic findings of placenta accreta. Gray-scale B-mode transabdominal sonography and Color Doppler Ultrasound scans were done. The overall accuracy of diffuse or focal lacunar flow was $73.3 \%$, vascular lakes with turbulent flow 70\%, Hypervascularity of serosa bladder interface $62 \%$ and markedly dilated vessel over peripheral sub-placental zone $71 \%$ in doppler ultrasound. Color Doppler does not appear to improve the accuracy of Gray-Scale so, it is suggested to use both Gray scale ultrasound and Color Doppler in all cases of placenta previa with previous C.S to find out features that suggest presence of placenta accreta.
\end{abstract}

Keywords : Placenta Previa, Placental myometrial invasion, Cesarean section.

\section{Introduction}

Acquaintance. Morbidly follower placenta is asignificant reason for maternal morbidity, mortal sin and monstrous obstetric discharge. It may be characterized as a abnormal placental adherence Possibly clinched alongside entirety or To some degree of the placenta of the underlying uterine divider. It may be a conceivably an aggregation debilitating condition answerable for $7-10 \%$ about maternal mortal sin [4].

Three major variants for adhernt placentation camwood be distinguished as stated by those degree for trophoblastic Attack through those myometrium and the uterine serosa: placenta accreta ,placenta increta What's more placenta percreta [3].

Placenta accreta most likely speaks to those mossycup oak normal variant about abnormally follower placenta, What's more the sum varieties of obtrusive placentation need aid connected with a critical build for maternal morbidity, particularly because of blood loss, harm on nearby organs, compelling reason to Dire hysterectomy Furthermore postoperative difficulties [5].

The finding for placenta previa accreta could a chance to be carried out Eventually Tom's perusing utilizing gray-scale sonography. All the more recently, color doppler ultrasonography need been proposed to support in the analysis about placenta previa accreta as a result it highlights abnormal regions of hypervascularity for widened blood vessels inside the placental What's more uterine tissues [9].

Punctual analysis camwood move forward the perinatal prognosis by empowering arrangements for a workable obstetric crisis on be committed for example, such that hysterectomy Also enormous transfusion [1].

Those point about this consider may be will assess the correctness from claiming color doppler ultrasonic in antenatal analysis about placenta previa accreta clinched alongside patients for past cesarean segments.

\section{Subjects and methods}

Those contemplate incorporated 60 pregnant females then afterward 28 week about gestation starting with obstetrics Furthermore gynecology Branch for Banha school healing facility Throughout An time starting with (1st for december 2018 on 30th november 2019) for suspected historical backdrop and ultrasonographic discoveries from claiming placenta accreta. An composed full educated assent might have been taken starting with every tolerant should take an interest in the investigation. Consideration criteria were Pregnant female in the third trimesters, past cesarean scar, Hemodynamically stable at the run through of the ultrasonography examination with determine the abnormal placentation What's more Placenta previa foremost. Same time patients who would actively bleeding, Gestational period under 28 weeks, placenta that might have been found posteriorly What's more Primi gravide were excluded.

Gray-scale B-mode transabdominal sonography might have been to start with used to screen those placental tissue for An precise design. Cautious consideration might have been paid of the homogeneity Also echogenic examples of the placenta. Ultrasonography examination might have been done with those bladder incompletely filled should consider ideal visualization of the uterine serosa toward the bladder divider interface.

Nonattendance of the regularly unmistakable retroplacental hypoechoic zone, vicinity for placental sonolucent spaces (with their example of distribution) or irregularities of the bladder-uterine serosa were noted. Estimation of the littlest myometrial thickness (SMT) might have been got and it quell the range of best weakening or diminishing of the myometrium during the webpage of placental implantation.

The sum situations were subjected to trans-abdominal 
shade doppler assessment the place color signs were superimposed onto the gray-scale picture with assess those variable uteroplacental vascular morphologic examples. Exceptional consideration might have been paid of the placental-myometrial interface and the placentas, over situations of previa. They were likewise assessed for the vicinity of expansive abnormal intraplacental lakes.

\section{Results}

Table (1) shows that the age of the studied group ranged from 22 to 46 years with a mean of $31.6 \pm 4.6$ years. Their parity ranged from 1 to 6 with a median of 2 . All patients had at least one previous cesarean delivery, the median number of previous cesarean sections was 3 (range: 1-4). The mean gestational age was $34.8 \pm 2.5$ weeks

Table (2) shows that the overall accuracy of loss of the retro-placental sono lucent zone was $78.3 \%$, irregular retro-placental sono lucent zone $75 \%$, irregularity of uterine bladder interface $61.7 \%$ and abnormal placental lacunae $72 \%$ in $2 \mathrm{D}$ ultrasound.

Table (3) In this table, the overall accuracy of diffuse or focal lucent flow was $73.3 \%$, vascular lakes with turbulent flow $70 \%$, Hypervascularity of serosa bladder interface $62 \%$ and markedly dilated vessel over peripheral sub-placental zone $71 \%$ in color doppler ultrasound.

Table (4) shows that There were 32cases diagnosed accreta according to color doppler and 24 cases were diagnosed accreta intraoperatively with significant difference $(\mathrm{p}$ value $=0.001)$.

Fig (1) shows ROC curve for color Doppler US which had $88.2 \%$ sensitivity and $75 \%$ specificity for placenta accreta diagnosis.

Table (5) shows that sensitivity, specificity, PPV and NPV of Doppler US were 88.2\%,75\%,69.8\%,87\% respectively for placenta accreta diagnosis.

Table (1) Demographic characteristics of patients with placenta previa.

\begin{tabular}{lc}
\hline $\mathbf{N}=\mathbf{6 0})$ & Mean \pm SD \\
\hline Age $_{(\text {years) }}$ & $31.6 \pm 4.6(22-46)$ \\
Gravidity $_{\text {Parity }}$ & $4(2-9)$ \\
Previous C.S & $2(1-6)$ \\
G.A $_{(\text {weeks) }}$ & $3(1-4)$ \\
\hline
\end{tabular}

Table (2) Findings of transabdominal 2D ultrasound in accreta and non accreta groups.

\begin{tabular}{|c|c|c|c|c|c|c|c|c|}
\hline & \multicolumn{2}{|c|}{ Intraoperative findings } & \multirow[t]{2}{*}{ Sensitivity } & \multirow[t]{2}{*}{ Specificity } & \multirow[t]{2}{*}{ PPV } & \multirow[t]{2}{*}{ NPV } & \multirow[t]{2}{*}{ Accuracy } & \multirow[t]{2}{*}{ P-value } \\
\hline & $\begin{array}{c}\begin{array}{c}\text { Accreta } \\
(\mathbf{n}=24)\end{array} \\
\mathbf{N}(\%)\end{array}$ & $\begin{array}{c}\begin{array}{c}\text { Not accrete } \\
(\mathbf{n}=\mathbf{3 6})\end{array} \\
\mathbf{N}(\%)\end{array}$ & & & & & & \\
\hline Loss of the & & & & & & & & \\
\hline $\begin{array}{l}\text { retro-placental } \\
\text { sono lucent } \\
\text { zone }\end{array}$ & $\begin{array}{c}21 \\
(87.5 \%)\end{array}$ & $\begin{array}{c}16 \\
(44 \%)\end{array}$ & $91.2 \%$ & $85.5 \%$ & $75.6 \%$ & $82.4 \%$ & $78.3 \%$ & $<0.001 *$ \\
\hline $\begin{array}{l}\text { Irregular } \\
\text { retro-placental } \\
\text { sono lucent } \\
\text { zone }\end{array}$ & $\begin{array}{c}20 \\
(83.3 \%)\end{array}$ & $\begin{array}{c}13 \\
(36.1 \%)\end{array}$ & $95.8 \%$ & $82 \%$ & $76.2 \%$ & $82.4 \%$ & $75 \%$ & $<0.001^{*}$ \\
\hline $\begin{array}{l}\text { Irregularity of } \\
\text { uterine bladder } \\
\text { interface }\end{array}$ & $\begin{array}{c}18 \\
(75 \%)\end{array}$ & $\begin{array}{c}9 \\
(25 \%)\end{array}$ & $82.4 \%$ & $71.4 \%$ & $62.2 \%$ & $60 \%$ & $61.7 \%$ & $<0.001^{*}$ \\
\hline $\begin{array}{l}\text { Abnormal } \\
\text { placental } \\
\text { lacunae }\end{array}$ & $\begin{array}{c}15 \\
(62.5 \%)\end{array}$ & $\begin{array}{c}10 \\
(27.8 \%)\end{array}$ & $92.2 \%$ & $75.5 \%$ & $61.9 \%$ & $65.6 \%$ & $72 \%$ & $<0.001^{*}$ \\
\hline
\end{tabular}

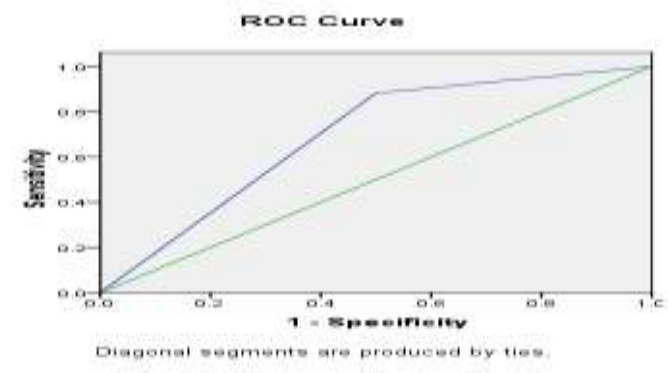

Fig (1) ROC curve of Color Doppler Ultrasound in Placenta Accreta 
Table (3) Findings of color doppler ultrasound in accreta and non accreta groups.

\begin{tabular}{|c|c|c|c|c|c|c|c|c|}
\hline & \multicolumn{2}{|c|}{ Intraoperative findings } & \multirow[b]{3}{*}{ Sensitivity } & \multirow[b]{3}{*}{ Specificity } & \multirow[b]{3}{*}{ PPV } & \multirow[b]{3}{*}{ NPV } & \multirow[b]{3}{*}{ Accuracy } & \multirow[b]{3}{*}{ P-value } \\
\hline & $\begin{array}{c}\text { Accreta } \\
(n=24)\end{array}$ & $\begin{array}{c}\text { Not accrete } \\
(n=36)\end{array}$ & & & & & & \\
\hline & $\mathbf{N}(\%)$ & $\mathbf{N}(\%)$ & & & & & & \\
\hline $\begin{array}{l}\text { Diffuse or focal } \\
\text { lacunar flow }\end{array}$ & $\begin{array}{c}23 \\
(95.8 \%)\end{array}$ & $\begin{array}{c}24 \\
(66.7 \%)\end{array}$ & $88.2 \%$ & $75 \%$ & $71.4 \%$ & $77.8 \%$ & $73.3 \%$ & $<0.001 *$ \\
\hline $\begin{array}{l}\text { Vascular lakes } \\
\text { with turbulent } \\
\text { flow }\end{array}$ & $\begin{array}{c}22 \\
(91.7 \%)\end{array}$ & $\begin{array}{c}20 \\
(83.3 \%)\end{array}$ & $85.3 \%$ & $63.4 \%$ & $63 \%$ & $64.3 \%$ & $70 \%$ & $<0.001 *$ \\
\hline $\begin{array}{l}\text { Hypervascularity } \\
\text { of serosa bladder } \\
\text { interface }\end{array}$ & $\begin{array}{c}21 \\
(87.5 \%)\end{array}$ & $\begin{array}{c}18 \\
(50 \%)\end{array}$ & $47.1 \%$ & $92.3 \%$ & $60 \%$ & $70 \%$ & $62 \%$ & $<0.001 *$ \\
\hline $\begin{array}{l}\text { Markedly dilated } \\
\text { vessel } \\
\text { peripheral } \\
\text { placental zone }\end{array}$ & $\begin{array}{c}20 \\
(83.3 \%)\end{array}$ & $\begin{array}{c}19 \\
(52.8 \%)\end{array}$ & $88.2 \%$ & $61.5 \%$ & $62 \%$ & $55.9 \%$ & $71 \%$ & $<0.001 *$ \\
\hline
\end{tabular}

Table (4) Relation between color doppler ultrasound diagnosis of placenta accreta and operative findings.

\begin{tabular}{|c|c|c|c|c|}
\hline & & \multicolumn{2}{|c|}{ Operative Findings } & \multirow[t]{2}{*}{ P-value } \\
\hline & & Accreta & No Accreta & \\
\hline Color doppler & Accreta $\mathrm{N}=32$ & $20(33.3 \%)$ & $12(20 \%)$ & $0.001 *$ \\
\hline Findings & No Accreta=28 & $4(6.7 \%)$ & $24(40 \%)$ & \\
\hline Total $N=60$ & & $24(40 \%)$ & $36(60 \%)$ & \\
\hline
\end{tabular}

Table (5) Diagnostic performance of the Doppler US criteria for diagnosis of placenta accrete.

\begin{tabular}{cccccccc}
\hline & AUC & P-value & Sensitivity & Specificity & PPV & NPV & Accuracy \\
\hline Doppler US & 0.69 & $0.012 *$ & $88.2 \%$ & $75 \%$ & $69.8 \%$ & $87 \%$ & $76.5 \%$ \\
\hline
\end{tabular}

\section{Discussion}

Placenta accreta (PA) happens when the chorionic villi attack those myometrium abnormally. It will be partitioned under three evaluations dependent upon histopathology: placenta accreta the place the chorionic villi are over contact for those myometrium, placenta increta the place the chorionic villi attack those myometrium, Furthermore placenta percreta the place the chorionic villi infiltrate those uterine serosa the hazard for placenta accreta is $24 \%$ Previously, ladies for placenta previa Furthermore you quit offering on that one former cesarean conveyance Furthermore $67 \%$ over ladies with placenta previa and three or more former cesarean conveyances [10].

Ultrasonic (US) need been those elementary symptomatic device for Dad and need been indicated on assistance on recognize this confusion On 50\%-80\% about cases. Those climbing cesarean area rate Also resultant expanded predominance about Dad have restored enthusiasm toward the us offers for this confusion [2].

An investigation carried out by [11], exhibited that antenatal finding for placenta accreta will be connected with An diminishment to blood passing. There might have been a statistically noteworthy distinction between conveyances from claiming prenatally diagnosed placenta accreta contrasted with false-negative cases, for lesquerella peripartum blood reduction $(1300$ vs $3000 \mathrm{~mL}$ ) and shorter hospitalization in the frigid (2 vs 4 days).

As stated by the literature, visualization of lacunae need the most noteworthy affectability in the finding for PA, permitting ID number in $78 \%-93 \%$ of instances following 15 weeks gestation, with An specificity for 78 . $6 \%$. Expanding numbers from claiming lacunae are connected with expanded hazard to Dad. Constantly on situations from claiming Dad clinched alongside one study required in any event four placental lacunae [12]. A foremost myometrial thickness short of what $1 \mathrm{~mm}$ might have been showed up for a chance to be predictive for Dad by Twickler et al. , who uncovered this finding On nine of 10 situations for Dad [3].

To our study, there will be build in history about past c's. Encountered with urban decay because of deindustrialization, engineering imagined, government lodgin with development in maternal agdistis Likewise $15 \%$ between 35-39 quite some time old needed 3 former c. Encountered with urban decay because of deindustrialization, engineering imagined, government lodgin. $5 \%$ about ladies with maternal period $\geq 40$ A long time old required 3 former c's. S. There is measurable critical Contrast the middle of distinctive maternal 
agdistis bunches done historical backdrop of past c's. Encountered with urban decay because of deindustrialization, innovation developed, government lodgin $(\mathrm{p}<0.001)$.

This consider found that, $65 \%$ for patients needed no muddling. $15 \%$ required cesarean hysterectomy. Bladder harm might have been about( $8.3 \%)$. Frigid confirmation Also post-partum discharge were around (5\%). Imply blood transfusion might have been fundamentally higher Around accumulate bunch $(\mathrm{p}<0.001)$. While, imply hemoglobin level might have been essentially easier Around accreta assembly $(<0.001)$.

The outcomes of the current study exhibited that sensitivity, specificity, PPV, Furthermore same way as the NPV for 2D ultrasonography in analysis about Dad were affectability (95\%), specificity (85. 5\%), PPV (71\%), Also same way as the NPV (77\%) individually. Those vicinity about unpredictable retro-placental sono lucent zone needed the most astounding affectability ( 95 . $8 \%)$.

On our study, the color doppler sonographic criteria to Dad indicated that the generally precision about diffuse alternately central lacunar stream might have been 73 . $3 \%$, vascular lakes for turbulent stream $70 \%$, Hypervascularity about serosa bladder interface $62 \%$ and markedly widened vespula vulgaris over fringe subplacental zone $71 \%$. Clearly it is not better than Gray scale us.

A prospective consider starting with pakistan news person that the sensitivity, specificity, PPV, NPV, Also correctness from claiming ultrasonic were $85.7 \%, 83$. $3 \%, 66.7 \%, 93.8 \%$ and $84 \%$ separately [8].

An alternate consider done Alexandria, egypt news person that those practically normal ultrasonography features over foreseeing Dad were myometrial thickness $<1 \mathrm{~mm}$, disturbance from claiming urinary bladderuterine interface and the vicinity from claiming different placental sonolucent area, which might have been display altogether 4 affirmed accumulate instances [6].

A All the more later deliberate survey closed that ultrasonography is very delicate What's more particular in the prenatal analysis for Dad. They proposed Creating An prenatal screening protocol should enhance those result of this progressively that's only the tip of the iceberg as a relatable point significant obstetric muddling. The survey included 14 accomplice investigations directing, including 3889 pregnancies showing with placenta previa and 1 alternately more former cesarean conveyances. The affectability for prenatal ultrasonography might have been $90.9 \%$. Those pooled execution of ultrasonography to those antenatal identification from claiming placenta previa accreta might have been higher Previously, prospective over review studies, for An symptomatic chances proportions from claiming 228. 5 (95\% certainty interval, 67. 2-776. 9) What's more 80.8 (95\% certainty interval, 13. 0-501. 4), individually [7].

Overall, in [13] study, the analysis for abnormal connection of the placenta of the myometrium might have been right to $(100 \%)$ from claiming cases to doppler ultrasonography. Those affectability for the finding about placenta accreta might have been (100\%) for color doppler ultrasound, Furthermore (93. 7\%) to 2D ultrasonography. Specificity might have been (66. $6 \%$ ) with color doppler Also (77. 7\%) to 2D ultrasonography. Those most noteworthy certain predictive worth (PPV) might have been discovered done 2D ultrasonography (88\%), same time shade doppler required $84 \%$ PPV. Negative predictive quality (Npv) might have been (100\%) Furthermore (87. 5\%) to shade Doppler, What's more 2D ultrasound, individually. Shade doppler us diagnosed every last bit cases with a chance to be accreta intraoperatively. Affectability $(100 \%)$, ash scale us diagnosed $(93 \%)$ of situations found to be accreta intraoperatively Also just 2 instances were negatively diagnosed not will a chance to be accreta.

An nother investigation by Mclean et al. Including an expansive associate about gravid patients toward hazard to placenta accreta neglected with exhibit the incremental utilization of doppler us to placenta accreta progressions conveyance mode over An stratified Investigation. Such An investigation needed performed doppler us clinched alongside a little extent of the companion that might have been main 28. 7\% ( $\mathrm{n}=40 / 139)$, also constantly An review ponder handles a rate of us inclination in regards explanatory information [14].

\section{Conclusion}

- The prevalence of PA is increasing, and practitioners should be aware of this entity and its imaging features.

- Placenta previa and a prior history of cesarean section are the most significant risk factors for PA.

- US remains the primary screening modality of PA.

- 2D Gray scale has higher sensitivity than color Doppler in diagnosis of placenta accreta.

- The presence of Irregular retro-placental sono lucent zone had the highest sensitivity for detection of PA.

\section{Recommendations}

- Antenatal diagnosis of placenta accreta is mandatory to overcome the maternal and fetal morbidity and mortality.

- Thus it is suggested to use both Gray scale ultrasound and Color Doppler in all cases of placenta previa with previous C.S to find out features that suggest presence of placenta accreta. This allows the surgical team to deal with emergency condition and prepare for potential bleeding .

\section{References}

[1] D.H.Andrew, R.M.Thomas, Multiple repeat cesareans and the threat of placenta accreta: incidence, diagnosis, management. Clin Perinatol, Vol. 38, PP.285-96, 2011.

[2] W.C.Baughman, J.E.Corteville , R.R.Shah, Placenta accreta: spectrum of US and MR imaging findings. 
Radiographics;Vol. 28,PP. 1905-1916,2008.

[3] G.Cali, L.Giambanco, G.Puccio , F.Forlani , Morbidly adherent placenta: evaluation of ultrasound diagnostic criteria and differentiation of placenta accreta from percreta. Ultrasound in obstetrics \& gynecology, Vol.41(4), PP.406-412, 2013.

[4] A.Carrillo , E.Chandraharan, Management of morbidly adherent placenta.Obstet Gynaecol Reproduc Med, Vol.26(10), PP.28390, 2016.

[5] F.D'antoio, C.Iacovella , A.Bhide , Prenatal identification of invasive placentation using ultrasound: systematic review and meta-analysis. Ultrasound Obstet Gynecol , Vol. 44, PP.8-16, 2014.

[6] A.Hamisa, T.Manal, R.Ahmed, Role of Doppler US and MRI in diagnosis of placenta accreta.Alexandria J., of Medicine, Vol.51(3), PP. 225-230, 2015.

[7] E. Jauniaux , B. Amar, Prenatal ultrasound diagnosis and outcome of placenta previa accreta after cesarean delivery: a systematic review and metaanalysis. American J., of obstetrics and gynecology, Vol. 217(1), PP.27-36, 2017.

[8] K .Nawab, N .Sadaf, K.Majid, diagnostic accuracy of ultrasound (usg) and magnetic resonance imaging (mri) in prenatal diagnosis of placenta accreta taking operative findings as gold standard. pjr, Vol. 27(4), PP.226-232, 2017.

[9] J.C. Shih, J.M. Palacios, Y.N. Su, M.K. Shyu, C.H. Lin, S.Y. Lin, Role of three-dimensional power doppler in the antenatal diagnosis of placenta accreta: comparison with gray-scale and color doppler techniques. Ultrasound Obstet Gynecol, Vol. 33, PP.193-203, 2009.

[10] A.Tan, C.Cher Heng, C.Puccy, Perioperative endovascular internal iliac artery occlusion balloon placement in management of placenta accreta.American J., of Roentgenology, Vol.189(5), PP. 1158-1163, 2007.

[11] M.Tikkanen, J.Paavonen, M.Loukovaara , V. Stefanovic, Antenatal diagnosis of placenta accreta leads to reduced blood loss. Acta Obstet Gynecol Scand, Vol.90, PP. 1140-1146, 2011.

[12] J.Yang, C.N. u , E.Safad, Sonographic findings of placental lacunae and the prediction of adherent placenta in women with placenta previa totalis and prior Cesarean section.Ultrasound in Obstetrics and Gynecology, Vol. 28 (2), PP.178-182, 2006.

[13] H. Borg, A. Ossman, H .Salem, M. El-Hemedi, K. El-Shafie, R. Alarabawya, Color Doppler ultrasound in diagnosis of placenta accreta. Evidence Based Women's Health J.,, Vol. 8(3), PP.215-222, 2018.

[14] L.A. McLean, M.E. Heilbrun, A.G. Eller, A.M. Kennedy, P.J. Woodward, Assessing the role of magnetic resonance imaging in the management of gravid patients at risk for placenta accreta. Acad Radiol, Vol.18, PP.1175-1180, 2011. 